\title{
Left Ventricular Basal Anteroseptal Segment
}

National Cancer Institute

\section{Source}

National Cancer Institute. Left Ventricular Basal Anteroseptal Segment. NCI Thesaurus.

Code C127657.

The anteroseptal portion of the basal division of the left ventricular myocardium as determined using the AHA 17-Segment Model (Cerqueira et al., 2002). 